\title{
Cognitive performance and anxiety disorders in young mothers in southern Brazil: a cross-sectional study
}

Transtornos de ansiedade e desempenho cognitivo em jovens mães no sul do Brasil: um estudo transversal

Trastornos de ansiedad y desempeño cognitivo en jóvenes madres en el sur de Brasil: un estudio transversal

Edna Aparecida Lopes Bezerra Katakura ${ }^{1}$, Fábio Monteiro da Cunha Coelho², Mariana Bonati de Matos $^{3}$, Luciana de Avila Quevedo ${ }^{3}$, Bárbara Borges Rubin ${ }^{3}$, Jéssica Puchalski Trettim ${ }^{3}$, Carolina Coelho Scholl ${ }^{3}$, Gabriela Kurz da Cunha ${ }^{3}$, Luisa Siewerdt Amarilho ${ }^{3}$, Mariana Weizer ${ }^{3}$, Tailan Rutz Bartel $^{3}$, Ricardo Tavares Pinheiro ${ }^{3}$, Karen Amaral Tavares Pinheiro ${ }^{4}$.

\begin{abstract}
Objective: To examine the association between Anxiety Disorders (AD) and cognitive performance in young mothers at 30 months postpartum. Methods: This is a cross-sectional study nested to a follow-up study was conducted with 539 young mothers in the city of Pelotas, in southern Brazil. The ADs were evaluated with the Mini International Neuropsychiatric Interview (MINI PLUS), cognitive performance was screened with the Montreal Cognitive Assessment (MoCA). We used multiple linear regression analysis to explore the association between ADs and cognitive performance. Results: The total MoCA score was associated with the following variables: marital status $\beta=-0.86(95 \% \mathrm{Cl}-1.60 ;-0.13)$, education $\beta=1.22(95 \% \mathrm{Cl} 0.90 ; 1.53)$, occupation $\beta=1.03(95 \% \mathrm{Cl} 0.28 ; 1.79)$, Generalized Anxiety Disorder (GAD) $\beta=-2.28(95 \% \mathrm{Cl}-4.07 ;-0.50)$ and at least one $A D 30$ months postpartum $\beta=-0.10(95 \% \mathrm{Cl}-0.20 ;-0.00)$. Together, these variables were responsible for $16 \%$ of the variance in the total MoCA score, GAD being the variable with the strongest negative association. Conclusions: The results showed that sociodemographic variables, a GAD diagnosis and the presence of at least one $A D$ were significantly associated with low cognitive performance in young mothers at 30 months postpartum.
\end{abstract}

Keywords: Anxiety Disorders, Cognition, Women, Postpartum Period.

\section{RESUMO}

Objetivo: Examinar a associação entre Transtornos de Ansiedade (TA) e desempenho cognitivo em jovens mães 30 meses após o parto. Métodos: Trata-se de um estudo transversal, aninhado a uma coorte prospectiva, conduzida com 539 jovens mães, na cidade de Pelotas, no sul do Brasil. Os TA foram avaliados com o Mini International Neuropsychiatric Interview (MINI PLUS) e o desempenho cognitivo foi rastreado com o Montreal Cognitive Assessment (MoCA). Os dados foram analisados através de Regressão Linear múltipla para explorar a associação entre os TA e desempenho cognitivo. Resultados: O escore total do MoCA foi

\footnotetext{
1 Universidade Estadual do Norte do Paraná (UENP), Bandeirantes-PR.

2Universidade Federal de Pelotas (UFPel), Pelotas-RS.

3Universidade Católica de Pelotas (UCPel), Pelotas-RS. *E-mail: marianabonatidematos@gmail.com

${ }^{4}$ Universidade Federal do Rio Grande (FURG), Rio Grande-RS.
}

This work was supported by Fundação de Amparo à Pesquisa do Estado do Rio Grande do Sul, Grant/Award. Number: 11/1189-4. 
associado às seguintes variáveis: estado civil $\beta=-0,86$ (IC95\% $-1,60 ;-0,13$ ), escolaridade $\beta=1,22$ (IC95\% 0,$90 ; 1,53$ ), ocupação $\beta=1,03$ (IC 95\% 0,28;1,79), Transtorno de Ansiedade Generalizada (TAG) $\beta=-2,28$ (IC $95 \%-4,07 ;-0,50$ ) e pelo menos um TA 30 meses após o parto $\beta=-0,10$ (IC 95\% -0,20;-0,00). Juntas, essas variáveis foram responsáveis por $16 \%$ da variância no escore total do MoCA, sendo o TAG a variável com a associação negativa mais forte. Conclusão: Os resultados mostraram que as variáveis sociodemográficas, diagnóstico de TAG e a presença de pelo uma TA foram significativamente associadas a um menor desempenho cognitivo em jovens mães 30 meses após o parto.

Palavras-Chave: Transtornos de Ansiedade, Cognição, Mulheres, Período Pós-Parto.

\section{RESUMEN}

Objetivo: Examinar la asociación entre Trastornos de Ansiedad (TA) y desempeño cognitivo en jóvenes madres 30 meses después del parto. Métodos: Se trata de un estudio transversal, anidado a un estudio de cohorte, conducido con 539 jóvenes madres, en la ciudad de Pelotas, en el sur de Brasil. Los TA fueron evaluados con el Mini International Neuropsychiatric Interview (MINI PLUS), y lo rendimiento cognitivo fue rastreado con la Montreal Cognitive Assessment (MoCA). los datos fueron analizados a través de análisis de regresión lineal múltiple para examinar la asociación entre los TA y el rendimiento cognitivo. Resultados: La puntuación total de MoCA se asoció con las siguientes variables: estado civil $\beta=-0.86$ (IC del 95\%: 1.60; 0.13), nivel de educación $\beta=1.22$ (IC del 95\%: 0.90; 1.53), ocupación $\beta=1.03$ (IC 95\% 0.28; 1.79), Trastorno de ansiedad generalizada (TAG) $\beta=-2.28$ (IC 95\% -4.07; -0.50) y al menos un TA 30 meses después del parto $\beta=-0.10$ (IC 95\% $-0.20 ;-0.00$ ). En conjunto, estas variables representaron el $16 \%$ de la varianza en el puntaje total de MoCA, siendo TAG la variable con la asociación negativa más fuerte. Conclusión: Los resultados mostraron que las variables sociodemográficas, el diagnóstico de TAG y la presencia de al menos un TA se asociaron significativamente con un menor rendimiento cognitivo en madres jóvenes 30 meses después del parto.

Palabras clave: Trastornos de Ansiedad, Cognición, Mujeres, Periodo Posparto.

\section{INTRODUCTION}

Maternity has been identified as a vulnerable period for the occurrence of anxiety symptoms and an Anxiety Disorder $(A D)$, due to the physical and psychological changes experienced by a woman during this time (COATES R, et al., 2014; HIGET N, et al., 2014; ROSS LE e MCLEAN LM, 2006).

The literature suggests that $A D s$ are relatively common and still underestimated during the first year after childbirth; however, a recent meta-analysis estimates a prevalence of $8.5 \%$ for the diagnosis of some ADs postpartum (GOODMAN JH, et al., 2016). An AD negatively impacts the psychological well-being of the mother, and the anxiety undermines self-confidence, maternal affection, the perception of a child's happiness and the quality of life (ARTECHE A, et al., 2011; MISRI S e SWIFT E, 2015; RECK C, et al., 2012; TIETZ A, et al., 2014).

Moreover, an $A D$ is a risk factor for the occurrence of major depressive disorder (MDD) and suicide (PRENOVEAU J, et al., 2013; TAVARES D, et al., 2012). Among the potential consequences of an AD, cognitive impairment also stands out (CASTANEDA AE, et al., 2008).

Cognition refers to several important mental processes that are involved in performing everyday activities, such as attention, decision making, thinking, self-regulation, problem solving, language skills and memory (ETKIN A, et al., 2013). Dysfunctions in these processes may lead to functional impairments and social and emotional adjustment (ETKIN A, et al., 2013; FERRERI F, et al., 2011).

Regarding the impairment of maternal cognitive performance, much attention has been focused on the cognitive changes associated with pregnancy and puerperium, linking motherhood to cognitive deficits, 
especially in memory (FARRAR D, et al., 2014; HENRY JD e RENDELL PG, 2007; HENRY JF e SHERWIN BB, 2012 WORKMAN JL, et al., 2012). In contrast, studies assessing the cognitive functions of mothers diagnosed with ADs are uncommon. However, some studies involving other population groups have reported an association between the diagnosis of an AD and some cognitive impairment (CASTANEDA AE, et al., 2008).

Maternal cognitive performance plays an important role in not only the transmission of but also the longlasting consequences of psychiatric disorders between generations (STEIN A, et al., 2009). Recurrent negative thoughts, such as preoccupation, interfere with specific cognitive functioning features, particularly attention and the ability to respond to the environment. This interference may impair the mother's parental capacity and negatively affect the mother-child interaction (STEIN A, et al., 2009). Maternal mental health is important when interacting with children, because if the mother has any impairment, the care of the child may be neglected (TIETZ A, et al., 2014). In addition, investigations of cognition have clinical relevance for the understanding of ADs due to the potential impacts of maternal psychopathology on the development of the child and adolescent (GOODMAN JH, et al., 2016; STEIN A, et al., 2009; STEIN A, et al., 2012).

Thus, the identification of negative outcomes associated with ADs may contribute to the development of appropriate clinical interventions. We aimed to examine the association between ADs and cognitive performance in young mothers at 30 months postpartum, as well as to examine the relationship between sociodemographic factors and specific cognitive domains.

\section{METHODS}

A cross-sectional study nested to a follow-up study was conducted with a sample of pregnant teenagers (13-19 years old) who were recruited between October 2009 and March 2011 from 47 primary healthcare units and 3 public obstetric clinics in Pelotas, a city in southern Brazil. For this study, the data collection was performed between 2011 and 2013, and we included women who had a child up to 30 months of age to evaluate the presence of $A D s$ and to screen maternal cognition. The inclusion criteria were to be pregnant, up to 19 years old and live in the urban area of Pelotas, RS (Brazil).

The exclusion criteria were present some physical or cognitive disability that did not allow the understanding of the questionnaire. The sample size was calculated with a confidence level of $95 \%$ and power of $80 \%$ for a total of 486 young mothers. An extra $15 \%$ was added for possible losses and refusals, bringing the total to 559 young mothers.

All participants were asked to provide consent to take part in the study. Parents of women younger than 18 years old, were also informed about the study characteristics and they needed to sign the term of free and informed assent They were assured of anonymity and confidentiality in the reporting of the results. If written informed consent was obtained, an interview at the participant's home was scheduled to collect data regarding sociodemographic characteristics, psychiatric disorders and cognitive function. This study was approved by the Ethics Committee on Research at the Catholic University of Pelotas under protocol number 2011/19. The participants who were diagnosed with psychiatric disorders were referred to the psychiatric clinic of the Catholic University of Pelotas.

The Mini International Neuropsychiatric Interview (MINI PLUS) namely, the validated Portuguese version, was used to assess Ads. It is a semistructured diagnostic interview based on Diagnostic and Statistical Manual of Mental Disorders-IV (DSM-IV) and International Classification of Diseases-10 (ICD-10) criteria.

The MINI comprises 19 modules that explore 17 DSM-IV axis I disorders, the risk of suicide, and antisocial personality disorder. For analysis purposes, dichotomous variables were used to indicate the presence or absence of the diagnosis of the following disorders: Generalized Anxiety Disorder (GAD), Panic Disorder (PD), Social Anxiety Disorder (SAD), Post-Traumatic Stress Disorder (PTSD) and Obsessive-Compulsive Disorder (OCD) (AMORIM P, 2000).In addition, a dichotomous variable indicating the presence or absence of at least one $A D$ was used. The diagnoses were made by interviewers trained and supervised by an experienced psychologist. 
Cognitive performance was assessed by the Montreal Cognitive Assessment (MoCA), which is a brief cognitive screening instrument, which aims to detect mild cognitive impairment. The MoCA measures eight cognitive domains: executive functions ( 4 points); visuospatial abilities (4 points); language (5 points); attention, concentration, and working memory (6 points); temporal and spatial orientation (6 points); and shortterm memory (5 points). The maximum score is 30 points, with higher scores indicating better cognitive performance (MEMÓRIA CM, et al., 2013). The test has good psychometric properties for screening cognition in various disorders (FREITAS S, et al., 2012).

Application time of approximately 10 minutes and the instructions for application and correction are described in a manual (NASREDDINE ZS, et al., 2005). Based on the cognitive domains of the test and for analysis purposes, a continuous variable was created with the total score in MoCA, and another continuous variable was generated for each domain cognitive.

A self-report questionnaire was used to obtain socio-demographic data from the mothers: age (up to 18 years/19 to 20 years/ above 21 years, marital status (living with a partner/living without a partner), education (less than 4 years/between 4 and 7 years/between 8 and 10 years/above 11 years), occupation (work or school/no occupation) and socioeconomic status $(A+B / C / D+E)$. We assessed socioeconomic according to the Economic Classification for Brazil from the Brazilian Association of Companies and Research. This classification is based on the accumulated material assets of the family and the education of the head of the family. Subjects are categorized into five classes from A (highest socioeconomic status) to E (lowest socioeconomic status). For this study, the classes were grouped as follows: High classes $(A+B)$, middle class (C) and lower classes (D+E) (ABEP, 2009).

For statistical analysis, we used SPSS (Statistical Package for the Social Science) program, version 22.0. The descriptive analysis was obtained by absolute and relative frequency and the bivariate analysis was performed through the $t$ test and ANOVA, to verify differences in the means. A multiple linear regression model was employed to estimate the effects of independent variables on the outcome and to control for possible confounding factors. The variables with $p$-value $<0.20$ entered in the multiple linear regression analysis with a hierarchical multilevel approach, using the cognitive performance as primary outcome (VICTORA CG, et al., 1997).

A multiple linear regression model was generated for each outcome: one for the total score and one for the score of each cognitive domain, as stated in MoCA. In the first level, sociodemographic and economic variables were included (age; marital status; educational; and occupation) and presence of a major depressive episode. In the second level, the ADs (GAD; SAD; PD; PTSD; OCD; and AD) were included. Each AD was adjusted to sociodemographic variables and major depressive episode separately.

\section{RESULTS}

Among the 559 eligible young mothers, 3.6\% $(n=20)$ refused to participate, resulting in 539 participants. The prevalence of psychiatric disorders diagnosed 30 months postpartum were as follows: GAD $5.5 \%$ ( $n=28$ ), SAD 9.2\% ( $n=47)$, PD 3.7\% ( $n=19)$, PTSD 4.3\% ( $n=22)$, and OCD $12.3 \%(n=63)$. The presence of at least one AD was detected in $21.5 \%(n=110)$ of the sample. Regarding the sociodemographic variables, $45.3 \%(n=244)$ of the participants were above 21 years old, most young mothers reported living with a partner (53.7\%) $(n=289)$, and $69.3 \%(n=355)$ were classified as socioeconomic status C. For education, $39.8 \%(n=214)$ had between 4 to 7 years of education, and $63.6 \%(n=343)$ did not work professionally (Table 1).

In the bivariate analysis, we observed that education $(p<0.001)$, socioeconomic status $(p<0.001)$ and occupation $(p=0.005)$ were positively associated with the total MoCA score. In contrast, all psychiatric variables except for PD showed a negative correlation with the total MoCA score. Thus, the lowest average total MoCA score was identified in young mothers with GAD 17.0 SD $\pm 5.7(p<0.001)$, SAD 18.3 SD $\pm 5.7(p=0.006)$, PTSD 17.9 SD $\pm 4.2(p=0.022)$, and OCD 18.4 SD $\pm 5.6(p=0.003)$. Young mothers who were diagnosed with at least one AD 30 months postpartum had a lower mean total MoCA score of $18.4 \mathrm{SD} \pm 5.1(p<0.001)$ than mothers who did not have the disorder (Table 1). 
Table 1 - Sample distribution according sociodemographic characteristics, anxiety disorders and total Montreal Cognitive Assessment scores (MoCA), $n=539$. Pelotas-RS, Brazil, 2009-2011.

\begin{tabular}{|c|c|c|c|c|}
\hline Variables & $\mathbf{N}$ & $\%$ & $\begin{array}{c}\text { Total MoCA } \\
\text { Mean } \pm \text { SD }^{*}\end{array}$ & p-value \\
\hline Age & & & & 0.093 \\
\hline Up to 18 years & 83 & 15.4 & $19.1 \pm 4.0$ & \\
\hline 19 to 20 years & 212 & 39.3 & $19.9 \pm 4.4$ & \\
\hline Above 21 years & 244 & 45.3 & $20.4 \pm 4.5$ & \\
\hline Marital status & & & & 0.063 \\
\hline Living with a partner & 289 & 53.7 & $20.3 \pm 4.3$ & \\
\hline Living without a partner & 249 & 46.3 & $19.6 \pm 4.5$ & \\
\hline Education & & & & $<0.001$ \\
\hline Less than 4 years & 40 & 7.4 & $16.2 \pm 4.6$ & \\
\hline Between 4 and 7 years & 214 & 39.8 & $18.8 \pm 4.1$ & \\
\hline Between 8 and 10 years & 194 & 36.1 & $21.1 \pm 3.8$ & \\
\hline Above 11 years & 90 & 16.7 & $22.1 \pm 4.4$ & \\
\hline Occupation & & & & 0.005 \\
\hline Work or school & 196 & 36.4 & $20.7 \pm 4.4$ & \\
\hline No occupation & 343 & 63.6 & $19.6 \pm 4.4$ & \\
\hline Socioeconomic status & & & & $<0.001$ \\
\hline$A+B$ & 84 & 16.4 & $21.6 \pm 3.4$ & \\
\hline $\mathrm{C}$ & 355 & 69.3 & $20.2 \pm 4.4$ & \\
\hline $\mathrm{D}+\mathrm{E}$ & 73 & 14.3 & $17.7 \pm 4.4$ & \\
\hline GAG & & & & $<0.001$ \\
\hline Yes & 28 & 5.5 & $17.0 \pm 5.7$ & \\
\hline No & 483 & 94.5 & $20.2 \pm 4.3$ & \\
\hline SAD & & & & 0.006 \\
\hline Yes & 47 & 9.2 & $18.3 \pm 5.7$ & \\
\hline No & 465 & 90.8 & $20.2 \pm 4.2$ & \\
\hline PD & & & & 0.087 \\
\hline Yes & 19 & 3.7 & $18.3 \pm 4.5$ & \\
\hline No & 493 & 96.3 & $20.1 \pm 4.4$ & \\
\hline PTSD & & & & 0.022 \\
\hline Yes & 22 & 4.3 & $17.9 \pm 4.2$ & \\
\hline No & 490 & 95.7 & $20.1 \pm 4.4$ & \\
\hline OCD & & & & 0.003 \\
\hline Yes & 63 & 12.3 & $18.4 \pm 5.6$ & \\
\hline No & 449 & 87.7 & $20.2 \pm 4.2$ & \\
\hline AD (least one) & & & & $<0.001$ \\
\hline Yes & 110 & 21.5 & $18.4 \pm 5.1$ & \\
\hline No & 401 & 78.5 & $20.4 \pm 4.1$ & \\
\hline Total & 539 & 100.0 & & - \\
\hline
\end{tabular}

Subtitle: $\mathrm{GAD}=$ Generalized Anxiety Disorder; $\mathrm{SAD}=$ Social Anxiety Disorder; PD=Panic Disorder; PTSD=Post-Traumatic Stress Disorder; $\mathrm{OCD}=$ Obsessive-Compulsive Disorder; $\mathrm{AD}=\mathrm{Anxiety}$ Disorder; Mean $\pm \mathrm{SD}=\mathrm{Data}$ are presented as the mean \pm Standard Deviation. Source: Katakura EALB, et al., 2011-2013.

The ADs were associated with specific domains of cognition. Young mothers with GAD had a lower average performance in four areas: executive function $0.7 \mathrm{SD} \pm 1.1(p=0.037)$, visuospatial ability $1.3 \mathrm{SD} \pm 0.9(p=0.016)$, language 3.0 SD $\pm 1.5(p=0.036)$, and temporal and spatial orientation $5.2 S D \pm 1.2(p=0.008)$. The women presenting with $S A D$ had a lower average performance in the areas of language $3.1 S D \pm 1.2(p=0.019)$ and temporal and spatial orientation $5.3 \mathrm{SD} \pm 1.0(\mathrm{p}=0.036)$. The women presenting with $\mathrm{PD}$ a had lower average performance only in the field of language $2.7 \mathrm{SD} \pm 1.3(\mathrm{p}=0.011)$. Young mothers with PTSD had a lower average cognitive performance in executive function $0.5 \mathrm{SD} \pm 0.6(\mathrm{p}=0.006)$ and short-term memory $2.3 \mathrm{SD} \pm 1.6$ $(p=0.025)$. The women with OCD had a lower average performance in the areas of language $3.1 \mathrm{SD} \pm 1.3$ $(p=0.033)$ and short-term memory $2.5 \mathrm{SD} \pm 1.6(p=0.010)$. Young mothers with at least one AD 30 months postpartum had a lower average performance in the areas of language $3.2 S D \pm 1.3 \quad(p=0.007)$, attention, concentration and working memory $3.7 \mathrm{SD} \pm 1.6 \quad(\mathrm{p}=0.004)$, temporal and spatial orientation $5.4 \mathrm{SD} \pm 0.8$ $(p=0.039)$, and short-term memory $2.5 \mathrm{SD} \pm 1.6(p=0.001)$ (Table 2). 
Table 2: Bivariate analysis, mean and standard deviation (SD) of anxiety disorders, specific areas of cognition and total Montreal Cognitive Assessment scores (MoCA) scores, $n=539$. Pelotas-RS, Brazil, 2009-2011.

\begin{tabular}{|c|c|c|c|c|c|c|c|c|c|c|c|c|}
\hline \multirow[t]{2}{*}{ Variables } & \multicolumn{2}{|c|}{ Executive function } & \multicolumn{2}{|c|}{ Visuospatial ability } & \multicolumn{2}{|c|}{ Language } & \multicolumn{2}{|c|}{$\begin{array}{c}\text { Attention, } \\
\text { concentration, } \\
\text { and working memory }\end{array}$} & \multicolumn{2}{|c|}{$\begin{array}{c}\text { Temporal and spatial } \\
\text { orientation }\end{array}$} & \multicolumn{2}{|c|}{ Short-term memory } \\
\hline & Mean士SD & p-value & Mean \pm SD & p-value & Mean \pm SD & p-value & Mean士SD & p-value & Mean $\pm S D$ & p-value & Mean $\pm S D$ & p-value \\
\hline GAD & & 0.037 & & 0.016 & & 0.036 & & 0.051 & & 0.008 & & 0.061 \\
\hline Yes & $0.7 \pm 1.1$ & & $1.3 \pm 0.9$ & & $3.0 \pm 1.5$ & & $3.5 \pm 1.6$ & & $5.2 \pm 1.2$ & & $2.5 \pm 1.7$ & \\
\hline No & $1.1 \pm 1.0$ & & $1.9 \pm 1.1$ & & $3.5 \pm 1.2$ & & $4.1 \pm 1.5$ & & $5.6 \pm 0.7$ & & $3.0 \pm 1.4$ & \\
\hline SAD & & 0.415 & & 0.430 & & 0.019 & & 0.170 & & 0.036 & & 0.188 \\
\hline Yes & $1.0 \pm 1.3$ & & $1.7 \pm 1.0$ & & $3.1 \pm 1.2$ & & $3.8 \pm 1.7$ & & $5.3 \pm 1.0$ & & $2.7 \pm 1.7$ & \\
\hline No & $1.1 \pm 1.0$ & & $1.9 \pm 1.1$ & & $3.5 \pm 1.2$ & & $4.1 \pm 1.5$ & & $5.6 \pm 0.7$ & & $3.0 \pm 1.4$ & \\
\hline PD & & 0.185 & & 0.851 & & 0.011 & & 0.417 & & 0.342 & & 0.145 \\
\hline Yes & $0.8 \pm 1.0$ & & $1.8 \pm 1.3$ & & $2.7 \pm 1.3$ & & $3.8 \pm 1.4$ & & $5.4 \pm 0.8$ & & $2.5 \pm 1.7$ & \\
\hline No & $1.1 . \pm 1.0$ & & $1.8 \pm 1.1$ & & $3.5 \pm 1.2$ & & $4.1 \pm 1.6$ & & $5.5 \pm 0.7$ & & $3.0 \pm 1.4$ & \\
\hline PTSD & & 0.006 & & 0.490 & & 0.073 & & 0.223 & & 0.413 & & 0.025 \\
\hline Yes & $0.5 \pm 0.6$ & & $1.7 \pm 1.1$ & & $3.0 \pm 1.1$ & & $3.7 \pm 1.6$ & & $5.4 \pm 0.8$ & & $2.3 \pm 1.6$ & \\
\hline No & $1.1 \pm 1.0$ & & $1.8 \pm 1.1$ & & $3.5 \pm 1.2$ & & $4.1 \pm 1.6$ & & $5.5 \pm 0.7$ & & $3.0 \pm 1.4$ & \\
\hline OCD & & 0.252 & & 0.317 & & 0.033 & & 0.142 & & 0.232 & & 0.010 \\
\hline Yes & $1.0 \pm 1.2$ & & $1.7 \pm 1.0$ & & $3.1 \pm 1.3$ & & $3.8 \pm 1.6$ & & $5.4 \pm 0.9$ & & $2.5 \pm 1.6$ & \\
\hline No & $1.1 \pm 1.0$ & & $1.9 \pm 1.1$ & & $3.5 \pm 1.2$ & & $4.1 \pm 1.5$ & & $5.6 \pm 0.7$ & & $3.0 \pm 1.4$ & \\
\hline $\begin{array}{l}\text { AD (least } \\
\text { one) }\end{array}$ & & 0.142 & & 0.142 & & 0.007 & & 0.004 & & 0.039 & & 0.001 \\
\hline Yes & $1.0 \pm 1.1$ & & $1.7 \pm 1.0$ & & $3.2 \pm 1.3$ & & $3.7 \pm 1.6$ & & $5.4 \pm 0.8$ & & $2.5 \pm 1.6$ & \\
\hline No & $1.2 \pm 1.0$ & & $1.9 \pm 1.1$ & & $3.6 \pm 1.2$ & & $4.2 \pm 1.5$ & & $5.6 \pm 0.7$ & & $3.1 \pm 1.4$ & \\
\hline
\end{tabular}

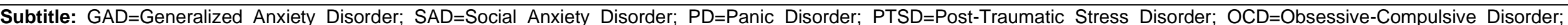
$A D=$ Anxiety Disorder; Mean $\pm S D=$ Data are presented as the mean \pm Standard Deviation.

Source: Katakura EALB, et al., 2011-2013. 


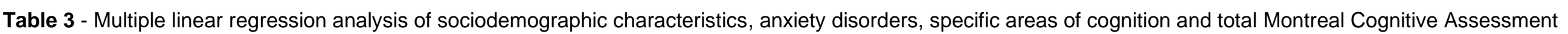
scores (MoCA) scores, n=539. Pelotas-RS, Brazil, 2009-2011.

\begin{tabular}{|c|c|c|c|c|c|c|c|c|c|c|c|c|c|c|}
\hline \multirow[t]{2}{*}{ Variables } & \multicolumn{2}{|c|}{$\begin{array}{l}\text { Executive } \\
\text { function }\end{array}$} & \multicolumn{2}{|c|}{$\begin{array}{l}\text { Visuospatial } \\
\text { ability }\end{array}$} & \multicolumn{2}{|c|}{ Language } & \multicolumn{2}{|c|}{$\begin{array}{l}\text { Attention, } \\
\text { concentration and } \\
\text { working memory }\end{array}$} & \multicolumn{2}{|c|}{$\begin{array}{c}\text { Temporal and } \\
\text { spatial orientation }\end{array}$} & \multicolumn{2}{|c|}{$\begin{array}{l}\text { Short-term } \\
\text { memory }\end{array}$} & \multicolumn{2}{|c|}{ Total MoCA } \\
\hline & $\beta$ & $95 \% \mathrm{Cl}$ & $\beta$ & $95 \% \mathrm{Cl}$ & $\beta$ & $95 \% \mathrm{Cl}$ & $\beta$ & $95 \% \mathrm{Cl}$ & $\beta$ & $95 \% \mathrm{Cl}$ & $\beta$ & $95 \% \mathrm{Cl}$ & $\beta$ & $95 \% \mathrm{Cl}$ \\
\hline Age & 0.06 & $-0.06 ; 0.18$ & 0.03 & $-0.10 ; 0.17$ & -0.01 & $-0.16 ; 0.13$ & 0.00 & $-0.18 ; 0.20$ & -0.02 & $-0.12 ; 0.06$ & 0.06 & $-0.12 ; 0.24$ & 0.04 & $-0.48 ; 0.56$ \\
\hline $\begin{array}{l}\text { Marital } \\
\text { status }\end{array}$ & -0.14 & $-0.32 ; 0.03$ & -0.18 & $-0.38 ; 0.01$ & -0.29 & $-0.50 ;-0.08^{*}$ & -0.10 & $-0.38 ; 0.17$ & -0.04 & $-0.18 ; 0.09$ & -0.01 & $-0.28 ; 0.25$ & -0.86 & $-1.60 ;-0.13^{*}$ \\
\hline Education & 0.30 & $0.23 ; 0.38^{* *}$ & 0.18 & $0.09 ; 0.26^{* *}$ & 0.38 & $0.29 ; 0.47^{* *}$ & 0.40 & $0.28 ; 0.51^{* *}$ & 0.04 & $-0.00 ; 0.10$ & 0.05 & $-0.06 ; 0.16$ & 1.22 & $0.90 ; 1.53^{* *}$ \\
\hline Occupation & 0.02 & $-0.16 ; 0.21$ & 0.20 & $0.00 ; 0.41^{*}$ & 0.17 & $-0.03 ; 0.39$ & 0.26 & $-0.01 ; 0.53$ & -0.02 & $-0.16 ; 0.12$ & 0.45 & $0.18 ; 0.71^{* *}$ & 1.03 & $0.28 ; 1.79^{\star}$ \\
\hline GAD & -0.31 & $-0.70 ; 0.07$ & -0.52 & $-0.95 ;-0.10^{*}$ & -0.50 & $-0.97 ;-0.02^{*}$ & -0.24 & $-090 ; 0.40$ & -0.38 & $-0.67 ;-0.09^{*}$ & -0.23 & $-0.87 ; 0.40$ & -2.28 & $-4.07 ;-0.50$ * \\
\hline SAD & -0.06 & $-0.46 ; 0.33$ & -0.08 & $-0.51 ; 0.35$ & -0.23 & $-0.69 ; 0.23$ & 0.13 & $-0.46 ; 0.73$ & -0.18 & $-0.48 ; 0.11$ & 0.13 & $-0.45 ; 0.71$ & -0.69 & $-2.31 ; 0.93$ \\
\hline PD & -0.02 & $-0.54 ; 0.48$ & 0.19 & $-0.35 ; 0.74$ & -0.51 & $-1.07 ; 0.05$ & 0.30 & $-0.44 ; 1.05$ & 0.02 & $-0.36 ; 0.40$ & -0.07 & $-0.82 ; 0.66$ & 0.47 & $-1.59 ; 2.53$ \\
\hline PTSD & -0.50 & $-0.94 ; 0.06^{*}$ & -0.04 & $-0.57 ; 0.47$ & -0.20 & $-0.75 ; 0.35$ & -0.08 & $-0.81 ; 0.63$ & -0.00 & $-0.37 ; 0.35$ & -0.34 & $-1.03 ; 0.34$ & -0.71 & $-2.65 ; 1.22$ \\
\hline OCD & -0.14 & $-0.53 ; 0.24$ & -0.09 & $-0.51 ; 0.33$ & -0.24 & $-0.69 ; 0.21$ & 0.13 & $-0.45 ; 0.71$ & -7.57 & $-0.29 ; 0.29$ & -0.07 & $-0.63 ; 0.49$ & -0.65 & $-2.22 ; 0.92$ \\
\hline AD & 0.01 & $-0.01 ; 0.04$ & 0.00 & $-0.02 ; 0.02$ & -0.01 & $-0.05 ; 0.01$ & -0.04 & $-0.07 ;-0.00^{*}$ & -0.00 & $-0.02 ; 0.01$ & -0.05 & $-0.08 ;-0.02^{\star *}$ & -0.10 & $-0.20 ;-0.00^{*}$ \\
\hline
\end{tabular}

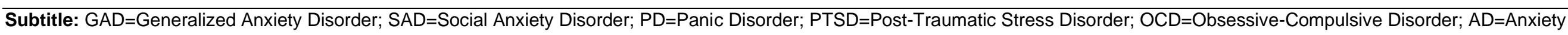
Disorder; $\beta=$ standardized coefficient; $95 \% \mathrm{Cl}=95 \%$ Confidence Interval; level of significance $\left(p<0.05^{*}, p<0.001^{* *}\right)$;

Each anxiety disorder was adjusted to sociodemographic variables and major depressive episode separately.

Source: Katakura EALB, et al., 2011-2013.

REAS/EJCH | Vol.11(17) | e2012 | DOI: https://doi.org/10.25248/reas.e2012.2019 Página 7 de 11 
In the multiple linear regression model, the total MoCA score was associated with the following variables: marital status $\beta=-0.86(95 \% \mathrm{Cl}-1.60 ;-0.13)$, education $\beta=1.22(95 \% \mathrm{Cl} 0.90 ; 1.53)$, occupation $\beta=1.03(95 \% \mathrm{Cl}$ $0.28 ; 1.79)$, GAD $\beta=-2.28(95 \% \mathrm{Cl}-4.07 ;-0.50)$ and at least one $A D 30$ months postpartum $\beta=-0.10(95 \% \mathrm{Cl}$ $0.20 ;-0.00)$. Together, these variables were responsible for $16 \%$ of the variance in the total MoCA score, GAD being the variable with the strongest negative association (Table 3).

The sociodemographic variables were associated with specific domains of cognition. Related to the marital status variable, not living with a partner was associated with a worse performance in language $\beta=-0.29(95 \% \mathrm{Cl}$ $-0.50 ;-0.08$ ), while having an occupation was associated with better performance in the following areas: visuospatial ability $\beta=0.20(95 \% \mathrm{Cl} 0.00 ; 0.4)$ and short-term memory $\beta=0.45(95 \% \mathrm{Cl} 0.18 ; 0.71)$. Regarding the education variable, higher education was associated with better performance in four areas: executive function $\beta=0.30(95 \% \mathrm{Cl} 0.23 ; 0.38)$, visuospatial ability $\beta=0.18(95 \% \mathrm{Cl} 0.09 ; 0.26)$, language $\beta=0.38(95 \% \mathrm{Cl}$ $0.29 ; 0.47)$, and attention, concentration and working memory $\beta=0.40(95 \% \mathrm{Cl} 0.28 ; 0.51)$ (Table 3).

In contrast, psychiatric variables were associated with worse performance in several areas. Young mothers with GAD showed worse performance in the following areas: visuospatial ability $\beta=-0.52(95 \% \mathrm{Cl}-0.95 ;-0.10)$, language $\beta=-0.50(95 \% \mathrm{Cl}-0.97 ;-0.02)$, and temporal and spatial orientation $\beta=-0.38(95 \% \mathrm{Cl}-0.67 ;-0.09)$. Those who had PTSD showed worse performance in executive function $\beta=-0.50(95 \% \mathrm{Cl}-0.94 ;-0.06)$. Young mothers with at least one AD 30 months postpartum had poorer performance in the following areas: attention, concentration and working memory $\beta=-0.04(95 \% \mathrm{Cl}-0.07 ;-0.00)$ and short-term memory $\beta=-0.05(95 \% \mathrm{Cl}$ $0.08 ;-0.02$ ) (Table 3).

\section{DISCUSSION}

This study aimed to investigate the association between ADs and cognitive performance and verify possible differences between the cognition domains of young mothers, as evaluated with the MoCA. In general, the results showed that low total scores in the MoCA were significantly associated with sociodemographic variables, with a GAD diagnosis and with the presence of at least one AD 30 months postpartum regardless of the presence of a depressive episode.

In our study the presence of at least one AD 30 months postpartum was associated with a worse performance in the total MoCA score and in the following areas: attention, concentration, working memory and short-term memory. Our results differ from the findings of a study that examined cognitive performance, symptoms of anxiety and depression and hormonal changes in nonpregnant and pregnant women, who were evaluated every pregnancy trimester and three months after delivery (FARRAR D, et al., 2014). The study reported impairment in spatial recognition memory, which started at the end of pregnancy and continued three months after delivery; however, the deficit was not associated with symptoms of anxiety and depression. The difference in the results may be due to the study scope and methodology.

However, a review study highlights that young adults may have significant cognitive impairment associated with ADs. Dysfunction in cognition has a strong clinical significance in these frequently progressive disorders, as they can reduce coping skills, increase patient susceptibility to relapse and affect treatment (CASTANEDA $\mathrm{AE}$, et al., 2008). In addition to mentioned consequences, changes in maternal cognition in the postnatal anxiety context may adversely affect the interaction between mother and baby. Anxious mothers tend to interact less and are less sensitive to their baby's' vocalizations (STEIN A, et al., 2012).

Among the ADs, GAD was associated with a worse cognitive performance in the total MoCA score and in specific areas, namely, visuospatial ability, language and temporal and spatial orientation. This result is consistent with those of studies reporting that GAD may be associated with cognitive impairment in young adults (TEMPESTA D, et al., 2013). For language performance, the result of this study is supported by the result of a study stating that the anxiety of young people is associated with low linguistic ability (TOREN $P$, et al., 2000). Regarding visuospatial ability and temporal and spatial orientation, our result differs from the finding of another study of GAD in young adults; the latter study highlights the maintenance of the areas of attention, non-verbal memory and executive function is these subjects (TEMPESTA D, et al., 2013). This difference may 
be due to the specific characteristics of the samples; the study of young adults with GAD examined a small sample of men and women, with and without the use of drugs, while our study included only women who were mothers in adolescence, which may have increased the cognitive demand linked to maternal care child. Nevertheless, more studies are needed to clarify this subject. In a mother with GAD, low attentional control affects the woman's ability to function as a mother, leading her to worry too much about the threats of the environment and to behave in overprotective way toward her baby (STEIN A, et al., 2009).

The cognitive performance of young mothers with PTSD was not associated with the total MoCA score at but was associated with a worse performance in executive function. This result is corroborated by studies suggesting that PTSD causes deficits in executive function (CASTANEDA AE, et al., 2008; ETKIN A, et al., 2013; POLAK AR, et al., 2012). Poor performance may not be strong enough to affect the performance of global cognition.

Another relevant result is the association between maternal cognitive performance and sociodemographic variables. In our study, education level was associated with the total MoCA score, suggesting that performance improves with increasing years of schooling. Higher levels of education were associated with better cognitive performances in the areas of executive function; visuospatial ability; language; and attention, concentration and working memory. Similar studies claim that cognitive performance tends to improve as the number of schooling years increases and that lower levels of education increase the probability of obtaining a lower overall MoCA score (FREITAS S, et al., 2012; RIBEIRO PCC, et al., 2010; ROSSETTI HC, et al., 2011). This association may be bidirectional. On the one hand, a higher level of education can increase cognitive performance. On the other hand, people who already have cognitive impairment may also have difficulties progressing to higher educational levels.

Another finding concerns the relationship between marital status and maternal cognitive performance. In our study, not living with a partner was associated with a worse performance in the total MoCA score and in the field of language. For the variable of not living with a partner, there is no consensus in the literature; several studies have reported better cognitive performances among married people, while another study found no relationship with cognitive performance (FREITAS S, et al., 2012; MORAES C, et al., 2010; RIBEIRO PCC, et al., 2010; WU MS, et al., 2011).

The same applies to the variable of occupation. In our study, having an occupation was associated with better maternal cognitive performance in relation to visuospatial ability and short-term memory. The literature is relatively scarce in terms of this variable. A previous study showed an association between occupation and cognitive performance, but in another screening study, this relationship was not confirmed (FREITAS S, et al., 2012; MORAES C, et al., 2010).

This present study should be interpreted in the context of its limitations. First, being a cross-sectional study, a causal relationship cannot be inferred between ADs and cognitive impairment. However, this study helps to identify groups of young mothers with risk factors for cognitive function impairment. Second, the period of assessment was not the usual postpartum period, which precludes comparisons with other studies that report evaluations during the postpartum period. However, we used a period in which the children were developing, and we used consolidating attachment styles. Thus, the impact of maternal mental health seems to be of strong significance. The third limitation is the instrument used. Although the MINI PLUS is an instrument with good sensitivity and reliability in the diagnosis of clinical cases, it may not have captured the full spectrum of anxiety symptoms that are usually seen in the population. Nevertheless, we identified young mothers with the full criteria of psychiatric disorders, reflecting a clinical population with a treatment demand.

\section{CONCLUSIONS}

Our findings show that maternal cognitive performance is associated with the diagnosis of at least one $A D$, and the diagnosis of GAD in a period of 30 months postpartum. By the time the parietal relationships are consolidated, appropriate clinical interventions are necessary to minimize the impacts of ADs on maternal health and protect the bonds between mother and baby. 


\section{FUNDIND AND ACKNOWLEDGEMENT}

This work was supported by and. We would like to thank the Fundação de Amparo à Pesquisa do Estado do Rio Grande do Sul, Grant/Award. Number: 11/1189-4.

\section{REFERENCES}

1. AMORIM P. Mini-Internacional Neuropsychiatric Interview (MINI): validação de entrevista breve para diagnóstico de transtornos mentais. Rev Bras. Psiquiatr. 2000;22(3):106-15.

2. ARTECHE A, et al. The effects of postnatal maternal depression and anxiety on the processing of infant faces. J Affect Disord. 2011;133(1):197-203.

3. Associação Brasileira de Empresas em Pesquisa (ABEP). [Critério de Classificação Econômica no Brasil]. http://www.abep.org/codigosguias/ABEP_CCEB.pdf.

4. CASTANEDA AE, et al. A review on cognitive impairments in depressive and anxiety disorders with a focus on young adults. J Affect Disord. 2008;106(1):1-27.

5. COATES $R$, et al. Women's experiences of postnatal distress: a qualitative study. BMC Pregnancy Childbirth. 2014;14(1):1-14.

6. ETKIN A, et al. A neurobiological approach to the cognitive deficits of psychiatric disorders. Dialogues Clin Neurosci. 2013;15(4):419-29.

7. FARRAR D, et al. Assessment of cognitive function across pregnancy using CANTAB: a longitudinal study. Brain Cogn. 2014;84(1):76-84.

8. FERRERI F, et al. Current research on cognitive aspects of anxiety disorders. Curr Opin Psychiatry. 2011; 24:49-54.

9. FREITAS S, et al. Montreal Cognitive Assessment: influence of sociodemographic and health variables. Arch Clin Neuropsychol. 2012;27(2):165-75.

10. FREITAS S, et al. Construct validity of the Montreal Cognitive Assessment (MoCA). J Int Neuropsychol Soc. 2012;18(02):242-50.

11. GOODMAN JH, et al. Anxiety disorders in postpartum women: a systematic review and meta-analysis. J Affect Disord. 2016; 203:292-331.

12. HENRY JF, SHERWIN BB. Hormones and cognitive functioning during late pregnancy and postpartum: a longitudinal study. Behav Neurosci. 2012;126(1):73-85.

13. HENRY JD, RENDELL PG. A review of the impact of pregnancy on memory function. J Clin Exp Neuropsychol. 2007;29(8):793-803.

14. HIGHET N, et al. Qualitative insights into women's personal experiences of perinatal depression and anxiety. Women Birth. 2014;27(3):179-84.

15. MEMÓRIA CM, et al. Brief screening for mild cognitive impairment: validation of the Brazilian version of the Montreal cognitive assessment. Int J Geriatr. Psychiatry. 2013;28(1):34-40.

16. MISRI S, SWIFT E. Generalized anxiety disorder and major depressive disorder in pregnant and postpartum women: maternal quality of life and treatment outcomes. J Obstet. Gynaecol. Can. 2015;37(9):798-803.

17. MORAES C, et al. Impact of sociodemographic and health variables on mini-mental state examination in a communitybased sample of older people. Eur Arch Psychiatr Clin Neurosci. 2010;260(7):535-42.

18. NASREDDINE ZS, et al. The Montreal Cognitive Assessment, MoCA: a brief screening tool for mild cognitive impairment. J Am Geriatr Soc. 2005;53(4):695-9.

19. POLAK AR, et al. The role of executive function in posttraumatic stress disorder: a systematic review. J Affect Disord. 2012;41(1):11-21.

20. PRENOVEAU J, et al. Postpartum GAD is a risk factor for postpartum MDD: the course and longitudinal relationships of postpartum GAD and MDD. Depress. Anxiety. 2013;30(6):506-14.

21. RECK C, et al. Effects of postpartum anxiety disorders and depression on maternal self-confidence. Infant Behv Dev. 2012;35(2):264-72.

22. RIBEIRO PCC, et al. Desempenho de idosos na bateria cognitiva CERAD: relações com variáveis sociodemográficas e saúde percebida. Psicol Reflex Crit. 2010;23(1):102-9.

23. ROSS LE, MCLEAN LM. Anxiety disorders during pregnancy and postpartum period: a systematic review. J Clinical Psychiat. 2006;67(8):1285-98.

24. ROSSETTI HC, et al. Normative data for the Montreal Cognitive Assessment (MoCA) in a population-based sample. Neurology. 2011;77(13):1272-5.

25. STEIN A, et al. The influence of postnatal psychiatric disorder on child development. Psychopathology. 2009;42(1):1121. 
26. STEIN A, et al. Maternal cognitions and mother-infant interaction in postnatal depression and generalized anxiety disorder. J Abnorm Psychol. 2012;121(4):795-809.

27. TAVARES D, et al. Prevalence of suicide risk and comorbidities in postpartum women in Pelotas. Rev. Bras. Psiquiatr. 2012;34(3):270-6.

28. TEMPESTA D, et al. Neuropsychological functioning in young subjects with generalized anxiety disorder with and without pharmacotherapy. Prog Neuropsychopharmacol Biol Psychiatry. 2013; 45:236-241.

29. TIETZ A, et al. Maternal bonding in mothers with postpartum anxiety disorder: the crucial role of subclinical depressive symptoms and maternal avoidance behaviour. Arch Womens Ment Health. 2014;17(5):433-42.

30. TOREN P, et al. Neurocognitive correlates of anxiety disorders in children: A preliminary report. J Anxiety Disord. 2000;14(3):239-47.

31. VICTORA CG, et al. The role of conceptual frameworks in epidemiological analysis: a hierarchical approach. Int J Epidemiol, 1997; 26(1):224-7.

32. WORKMAN JL, et al. Endocrine substrates of cognitive and affective changes during pregnancy and postpartum. Behav Neurosci, 2012;126(1):54-72.

33. WU MS, et al. Socio-demographic and health-related factors associated with cognitive impairment in the elderly in Taiwan. BMC Public Health, 2011;11:22. 